\title{
INTEGRATED INFORMATION SERVICE FOR PLUG-IN ELECTRIC VEHICLE USERS INCLUDING SMART GRID FUNCTIONS
}

\author{
Bálint CSONKA*, Csaba CSISZÁR \\ Dept of Transport Technology and Economics, Faculty of Transportation Engineering and Vehicle Engineering, \\ Budapest University of Technology and Economics, Hungary
}

Received 7 February 2017; revised 21 October 2017; accepted 24 November 2017

\begin{abstract}
Information provision can mitigate the drawbacks of electric vehicle use. In this paper, we elaborate an integrated Information Service (IS) for Plug-in Electric Vehicle (PEV) users that cover each process of use. The system elements and their relations are modelled. We deduce the functions from the negatives of electric vehicles compared to conventional ones. The information management processes are elaborated in detail. We focus on the charging and recharging periods considering dynamic electricity rates in the Smart Grid in order to minimalize the cost of charging from the user's perspective. We elaborate a cost saving method and evaluate the effects of dynamic tariff and forethoughtful behaviour. Since our proposed information, service covers each phase of use and reduces charging costs the presented solution simplifies electric vehicle use and improves efficiency. Furthermore, we elaborate the automatic charging scheduling methods that significantly reduce the charging cost and the fluctuation of the electricity demand.
\end{abstract}

Keywords: plug-in electric vehicle, information service, charging scheduling method, sensitivity analysis, smart grid.

\section{Nomenclature}

$B_{V 2 G}$ - benefit of supply mode;

$\mathrm{BEV}$ - battery electric vehicle;

$C_{p}, C_{s}$ - purchase and sale price of electricity from the user's point of view;

$C_{V 2 G}$ - cost of supply mode;

$D$ - input data of the SYS;

$E$ - amount of energy;

$E_{\text {opt }}$ - optimum amount of energy in supply mode;

$F_{j}$ - function $j$ of the SYS;

IS - information service;

MSP - map service provider;

$N_{i}$ - negative $i$ of PEVs;

$P_{V 2 G}-$ profit of supply mode;

PEV - plug-in electric vehicle;

$R_{c}(t)$ - current range of a PEV;

$R_{\text {min }}, R_{e, k}$ - safety range of the PEV and estimated distance of trip $k$;

SOC - state of charge;

SYS - information system;

$T_{G 2 V}, T_{V 2 G}$ - set of charging and supply time periods;

$\mathrm{U}$ - user;

$\mathrm{VM}$ - vehicle manufacturers.

\section{Introduction}

Environmental pollution caused by conventional propulsions and energy dependency create the right climate for alternative propulsion technologies in transportation. PEVs are either BEVs or plug-in hybrid electric vehicles. They stand out among the alternative fuel vehicles because of their many accomplishments like zero local emission and reduced maintenance cost.

Widespread of PEVs is expected in the near future especially in fleets. Governments also promote the usage with various tools. The most drastic measure is introduced in Norway that is the first country that forbids the sale of all fossil-fuelled cars from 2025.

The dissimilar operation of PEVs can be facilitated by integrated IS aiding personalised decisions and assisting traveller. Although several mobile or web-based applications are available that support and organise the use of PEVs, these solutions cover only some functions. There is currently no integrated application that assists the users during vehicle selection and in each phase of use. The main challenge is to organise and schedule the traveller's activities related to mobility to meet both the personal preferences and the vehicle operational constraints. Furthermore, the charging demands have to be conciliated

*Corresponding author. E-mail: csonka.balint@mail.bme.hu 
with the current capacity of the electrical grid. On one hand, PEVs cause additional load on the network, but on the other hand, each vehicle's battery is a power bank, that can reduce the fluctuation of electricity demands through supply operation (Hernández et al. 2012; Cowan 2013).

Our research aim was to model the integrated SYS and service in order to facilitate operation by adaptation of new technologies (e.g. Smart Grid). In the modelled IS both the user and the electricity network operator expectations have been taken into account at the same time. Each phase of PEV use has been covered, which is the main novelty of our approach. We focused on charging process applying Smart Grid technology in order to save operational costs. During the modelling, the following scientific issues were addressed:

- what are the conditions of the integration?

- what are the effects of the integrated IS?

- which variables how influence the user benefits in a Smart Grid?

- how does an advanced charging scheduling method reduce the cost of charging?

The literature review is provided in Section 1 to assess the current state-of-the-art. Then, we applied an analytic, system and process-oriented approach. After identification of the aims and functions, the system model has been summarised in Section 2. The operational model has been presented in Section 3. In Section 4, the charging scheduling method in smart-grid has been presented. In Section 5, the simulation of the use of charging scheduling is presented with a discussion. Finally, the conclusion has been drawn.

\section{Literature review}

At first, we identified the differences between the use of PEVs and use of conventional vehicles that may cause inconveniences for the travellers or require unusual driving behaviour. The outstanding differences are concerned with limited range, charging of batteries and high purchase price (Dagsvik et al. 2002; Hidrue et al. 2011; Krupa et al. 2014).

The inconvenient charging has been considered as a reason for aversion to PEVs in several studies (Hidrue et al. 2011; Caparello, Kurani 2012; Krupa et al. 2014). Compared to the refuel of a conventional vehicle, the charging of BEVs occurs more frequently and takes more time. Travellers' expectation is to spend the charging time useful (Philipsen et al. 2015). The current density of public charging points does not facilitate the convenient charging. These attributes together influence the route choice (Wang et al. 2016; Yang et al. 2016) and cause the "range anxiety". Because of the aforementioned characteristics of PEVs and charging network the travellers have to plan their routes in more detail in advance, that is also stated by Yang et al. (2016). This environment increases the importance of information provision about the conditions of PEV use because the negative effects can be significantly reduced or eliminated by advanced ISs. Since plug-in hybrid electric vehicles combine conventional and electric propulsion the range limitation is not remarkable and the difference in purchase price is less, but the benefits of IS, in this case, are also relevant.

The value of information is the main aspect of the development of the IS. Several studies examined the characteristics of information in transportation. Despite the peculiarities of information, it should be treated as other market goods (Wydro 2010), but the value can be negative too (Herrala 2007). Since advanced traveller information management has a significant impact on route and departure time choice, transportation network equilibrium can be obtained by using the IS (Rietveld 2011). Beside the user characteristics and the decision situation (Lawrence 1999), several other parameters may influence the value of information. The value of information is not constant in short-term for road transport; it is dependent on the current state of the network and varies through time and space (Wydro 2010). Herrala (2007) summarised several studies related to the value of information and defined 16 attributes that have an impact on it. Accuracy, reliability, timeliness, relevance and completeness were the five most often mentioned attributes.

Besides the content and traveller's personal characteristic, the communication channel and the way of interpretation also influence the value of information. In recent years, the travellers' information acquisition behaviour has been changed because of new technology. A research that examined the smartphone usage behaviour revealed that $75 \%$ of smartphone users use their device to navigate or gain traffic-related information (ThinkMobile 2011) and the most popular applications are weather, social networking, maps and navigation types of apps (Sutherland 2013). Esztergár-Kiss and Csiszár (2016) examined the trends in the development of route planner applications. They identified the functional integration, crowd-sourcing and use of real-time data as the most relevant advances, which correlates with user needs. Khoo and Asitha (2016) examined the user requirements of a mobile application. Realtime information was one of the key features. Accordingly, the most appropriate user interface between travellers and integrated SYS is the smartphone application. However, other communication channels such as web pages are also relevant.

Plenty of actors are involved in the charging process, but studies mainly focused on charging process from points of view of either electricity network operators or travellers. Consequently, on the one hand, the additional load on the network should be optimised to reduce the fluctuation of electricity demand. On the other hand, the goal is to optimise the timing of charging according to traveller preferences. Kiviluoma and Meibom (2011) assessed the charging from the aspect of electricity network by generating so-called power plant portfolios. According to their results, the cost of charging can be reduced up to $70 \%$ by charging planning and cost estimation in the case 
of variable rates. Guille and Gross (2009) focused on the supply operation and presented several services in order to levelize the demand on the system during off-peak conditions. However, the traveller's points of view have been disregarded in the research. Shao et al. (2009) propose a high-power charging during off-peak hours to efficiently utilize the free electric capacity. Hu et al. (2016) examined the charging process from aspects of PEV fleet operators. They presented centralised and decentralised strategies for charging planning. Both strategies eliminate loss of time. Mal et al. (2013) took into account preferences of both the travellers and the electricity network operators during the development of the charging planning method, which increases their benefits and their willingness to apply the method. Both the charging and the supply operation can be optimised by varying rates according to their algorithm. Their application requires user registration and supports solely the charging process. Csiszár and Földes (2015) revealed the connections of PEV charging management with other traveller information functions in a smart city. These correspondences were considered during modelling of the IS. Accordingly, the charging planning and supply mode are efficient tools to reduce the charging cost and the fluctuation in electricity demand.

The electrical grid is used by a PEV in a similar way like the road network is used by a conventional vehicle. Instead of movement, the charging process is the interaction between the PEV and the grid. Electric demand has also peak hours just like the travel demand and therefore proper timing has a key role especially in the case of dynamic rates. Hence, the importance of information on grid elements and use of smart technologies, or in other words, Smart Grid solutions in electricity network are promisingly increasing.

Although, these solutions have been investigated in previous works, but a deeper analysis of the impact of variables on cost saving has not been elaborated yet.

\section{Model of integrated SYS}

We define the following steps to model the integrated SYS:

- determination of the system architecture;

- revealing functions;

- elaboration of the data model.

\subsection{System architecture}

Figure 1 presents the system architecture with data connections. The "heart" of the system is the database, where data originating from several sources are stored logically together. We simplify the electric network and represent it as a single component; namely, the Smart Grid. We assume that the Smart Grid enables the flow of energy and information between vehicle and energy network in both directions alternately. There through, the fluctuation in grid load can be significantly reduced and less energy capacity is enough. Summarily, Smart Grid communicates with the SYS.

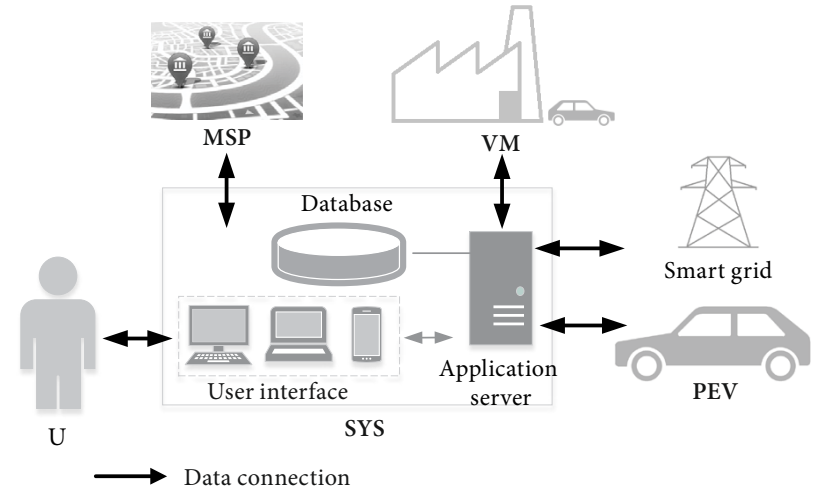

Figure 1. System architecture of integrated SYS

The MSP is connected to the SYS. It is the source of data related e.g. to transportation network and points of interest including also real-time data.

The SYS is accessible for users through different UIs like smartphone application, web page or on-board unit of intelligent PEV. The same functions can be performed via different platforms and different functions can be performed on the same platform; e.g., the user can plan the journey with the smartphone application, transmit it to the PEV and the navigation is performed in the vehicle.

Since strategically important data about the electric network and the interoperability are managed by the SYS, it should be operated by a national institute. It should regulate and manage the data storage and transfer between the participants. This institute grants access rights to data and provide information for the users.

\subsection{Functions of the system}

The primary aim of IS is to facilitate the efficient operation of the vehicles and the related electric grid. The secondary aim is to ensure benefits for each subsystem. The functions have been derived from the aims.

Based on literature review and our own experiences we defined six main negatives $N_{i}$ of PEVs. The key functions $F_{j}$ have been derived from these drawbacks. Figure 2 shows the correspondences between negatives and functions.

Vehicle selection function $F_{1}$ provides personalised decision support before purchase according to user requirements, vehicle attributes and user experiences (e.g. real range). The effect of the high purchase price $N_{1}$ can be mitigated in this manner as the user can choose a vehicle that meets his/her operational requirements. $F_{1}$ also mitigates the fear of new technology $N_{5}$ by providing information on PEV features.

Levels of the journey planning/navigation $F_{2}$ are:

- provides personalised information on transportation network and charging point conditions as well as plans route according to static data;

- plans route according to real-time data considering also the user and vehicle characteristics, the status of the transportation network and charging infrastruc- 
ture. The proper charging points along the journey can be reserved;

- determines the destination(s) according to the user's activities then it plans the route and charging process.

$\mathrm{F}_{2}$ mitigates the effects of limited range $\mathrm{N}_{2}$ because location-based and personalised information provision (also based on driving behaviour) can improve energy economy up to $10 \%$ (Zheng et al. 2015). Since the range of vehicle and availability of charging points are also taken into account the low density of charging points $\mathrm{N}_{3}$ is also managed by $F_{2}$. The charges can be classified as frequent charging at well-known locations, and occasional charging. The first group includes the charges that are performed at the owner's home, place of work or regularly visited facilities. In this case, the "main activity" is given (e.g. work, shopping), and charging is an additional service. In these cases, the charging time is usefully spent. The second group includes charges as main activities. In this case, $F_{2}$ mitigates the drawbacks of charging time $N_{4}$ by proposing available fast and superchargers instead of normal chargers or reduces the perceived charging time by the provision of information on how to spend the charging time in a productive or comfortable way. The range anxiety and the fear of new technology $N_{5}$ are decreased by the sense of confidence.

Charging assistance $F_{3}$ helps to start and finish charging process and provides information on the status of charging during the session. Payment is also supported by $F_{3}$. Charging time is reduced by information provision about the charging process to decide whether to finish the session or not. The charging can be also finished automatically having the user's demands been met. Accordingly, sense of long charging time $N_{4}$ and fear of new technology are significantly reduced $N_{5}$.

Charging scheduling function $F_{4}$ is an expansion to $F_{3}$. The aim is on one hand to reduce the charging cost and on the other hand to mitigate the negative effects of addition-

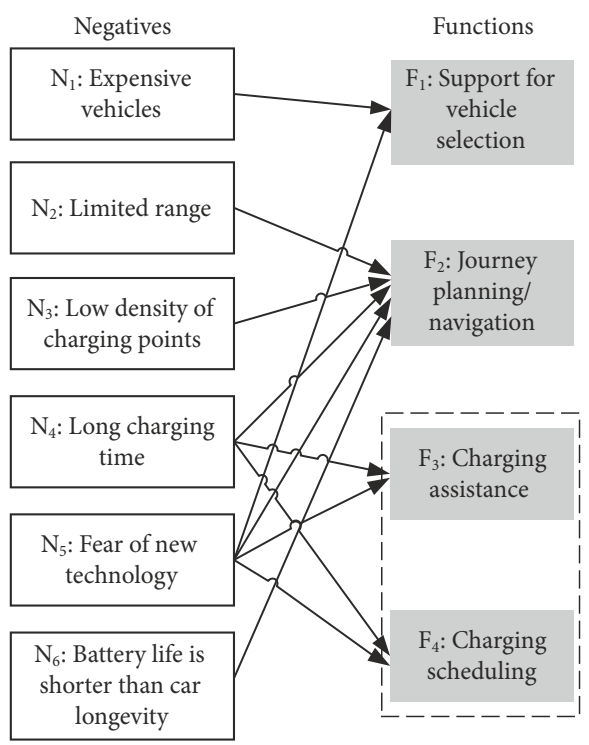

Figure 2. Functions of the IS derived from the negatives of PEV use al electric demand on the electrical grid by recognizing the demand characteristics and influencing the charging behaviour with consideration to the grid load. $F_{4}$ provides information about the terms and conditions (e.g. rates) of charging and supply operation. The charging is scheduled according to the current rates and demand characteristics. In this way, the decision support can be beneficial for both the user and the Smart Grid. The fear of new technology $N_{5}$ can be significantly mitigated by this advanced function and the battery life can be extended $N_{6}$ by information about the impact of the supply operation.

In Table 1, we summarised the correspondences among functions and phases of use, where " $\checkmark$ " symbol marks that which phase is supported by which function.

The functions inform or influence predominantly the users. However, the other participants may also benefit:

- Smart Grid: information provision on charging point availability reduces queue time and raises utilisation. Increasing charging demands can be served without capacity enhancement as a result of charging scheduling;

- VM: customer demand analysis is facilitated by data about utilisation.

The aim of integration is to combine the functions on the same interface and realise the activity-based travel management, where the application plans the journey according to the user characteristics and mobility needs, the attributes of transportation network, vehicle, charging infrastructure and environment. With the appearance of autonomous vehicles, activity-based travel management becomes increasingly important. Thus, the IS also facilitates the adoption of self-driving vehicles.

Table 1. The supported phases of PEV use by functions of the IS

\begin{tabular}{|c|c|c|c|c|c|}
\hline \multicolumn{2}{|c|}{ Phases of use } & $F_{1}$ & $F_{2}$ & $F_{3}$ & $F_{4}$ \\
\hline \multicolumn{2}{|c|}{ Selection (purchase) } & $\checkmark$ & & & \\
\hline \multicolumn{2}{|c|}{ Planning (journey, charging) } & & $\checkmark$ & & $\checkmark$ \\
\hline \multirow{2}{*}{ On route } & in movement & & $\checkmark$ & & \\
\hline & during stop & & & $\checkmark$ & $\checkmark$ \\
\hline
\end{tabular}

\subsection{Data-model of the system}

In the SYS various transportation-related data are stored (Table 2). In order to assign the data sets to the functions accurately, they have been divided into sub-functions (Table 3).

The subscript of a data set indicates the source. The superscript indicates whether the data group is static " $s$ " or dynamic " $d$ ". If the superscript is missing, the data set contains both dynamic and static data. Since several MSPs are available with advanced road network databases, the road network does not have to be stored in the database of SYS. Accordingly, the outer data stream is defined between the inner and an outer database. 
Table 2. Data sets for the IS

\begin{tabular}{|c|c|c|}
\hline Symbol & Name & Content \\
\hline$D_{U}^{S}$ & $\begin{array}{l}\text { static user } \\
\text { data }\end{array}$ & $\begin{array}{l}\text { e.g. preferred payment method, } \\
\text { driving behaviour in general, } \\
\text { feedback on electric vehicle use }\end{array}$ \\
\hline$D_{U}^{d}$ & $\begin{array}{l}\text { dynamic user } \\
\text { data }\end{array}$ & $\begin{array}{l}\text { e.g. expectations regarding } \\
\text { charging, services and route }\end{array}$ \\
\hline$D_{P E V}^{s}$ & $\begin{array}{l}\text { static vehicle } \\
\text { data }\end{array}$ & $\begin{array}{l}\text { e.g. battery capacity, maximum } \\
\text { range and charging power, type } \\
\text { of connector }\end{array}$ \\
\hline$D_{P E V}^{d}$ & $\begin{array}{l}\text { dynamic } \\
\text { vehicle data }\end{array}$ & $\begin{array}{l}\text { e.g. current range, state of charge, } \\
\text { location of vehicle }\end{array}$ \\
\hline$D_{\text {smart grid }}^{s}$ & $\begin{array}{l}\text { static Smart } \\
\text { Grid data }\end{array}$ & $\begin{array}{l}\text { e.g. type of charger, max. charging } \\
\text { power, accessibility }\end{array}$ \\
\hline$D_{\text {smart grid }}^{d}$ & $\begin{array}{l}\text { dynamic } \\
\text { Smart Grid } \\
\text { data }\end{array}$ & $\begin{array}{l}\text { e.g. rates, availability, charging } \\
\text { power, amount of energy, } \\
\text { conditions of supply operation }\end{array}$ \\
\hline$D_{V M}$ & $\begin{array}{l}\text { new electric } \\
\text { vehicle data }\end{array}$ & $\begin{array}{l}\text { e.g. range, charging power, type } \\
\text { of connector, cost }\end{array}$ \\
\hline$D_{M S P}$ & services & e.g. type of services and facilities \\
\hline
\end{tabular}

Table 3. Input data of sub-functions

\begin{tabular}{|c|c|c|}
\hline$F_{j}$ & Sub-function & Input \\
\hline$F_{1}$ & $\begin{array}{l}\text { calculation of operating cost and } \\
\text { return on investment }\end{array}$ & $D_{U}^{s}, D_{P E V}^{s}, D_{V M}$ \\
\hline \multirow{3}{*}{$F_{2}$} & $\begin{array}{l}\text { find suitable places (based on } \\
\text { activities) }\end{array}$ & $\begin{array}{l}D_{U}^{s}, D_{P E V}^{s}, D_{M S P}, \\
D_{\text {smart grid }}^{s}\end{array}$ \\
\hline & plan journey & $D_{M S P}, D_{P E V}^{s}$ \\
\hline & book charger & $D_{U}^{s}$ \\
\hline \multirow{5}{*}{$F_{3}$} & identify user and start charging & $D_{U}^{s}, D_{P E V}^{s}$ \\
\hline & $\begin{array}{l}\text { estimate charging time and create/ } \\
\text { modify charging point booking }\end{array}$ & $\begin{array}{l}D_{\text {smart grid }}^{d}, D_{U}^{d}, \\
D_{P E V}^{d}\end{array}$ \\
\hline & smart metering (price calculation) & $D_{\text {smart grid }}^{d}$ \\
\hline & end charge automatically & $\begin{array}{l}D_{U}^{d}, D_{P E V}^{d} \\
D_{\text {smart grid }}^{d}\end{array}$ \\
\hline & payment and account management & $D_{U}^{s}, D_{\text {smart grid }}^{d}$ \\
\hline \multirow{2}{*}{$F_{4}$} & charge only scheduling & $\begin{array}{l}D_{U}^{d}, D_{P E V}^{d}, \\
D_{\text {smart grid }}^{d}, D_{M S P}\end{array}$ \\
\hline & charge and supply scheduling & $\begin{array}{l}D_{U}^{d}, D_{P E V}^{d} \\
D_{\text {smart grid }}^{d}\end{array}$ \\
\hline
\end{tabular}

\section{Model of integrated IS}

After modelling the entire system, we modelled its operation, following the defined functions.

\subsection{Support for vehicle selection $\left(F_{1}\right)$}

Information on PEVs' characteristic specified by the VM is provided before purchase. Information about experi- ences of other users is also available here. If the user sets the driving behaviour and expectations (e.g. annual mileage, average distances), a PEV type meeting the requirements is recommended and personalised information on operating cost and return on investment is provided. By this decision support, the PEV user satisfaction can be significantly enhanced.

\subsection{Journey planning/navigation $\left(F_{2}\right)$}

The personalised and "vehiclized" journey can be planned (automatically) if the place of activities is given. The following aspects are to be considered during journey planning:

- driving behaviour (general user needs e.g. supercharger preference, influence of driving behaviour on energy consumption);

- vehicle characteristic (e.g. type of connector, range, average energy consumption);

- state of charging infrastructure (e.g. charging point availability, predicted charging time);

- transportation network parameters (e.g. distance between two chargers, current traffic situation).

If the intended activities are given without exact locations, the planning process takes also into account all possible places, as destinations. The main steps of the journey planning process have been summarized on Figure 3.

The general user needs and characteristics of driving behaviour are considered during journey planning, but

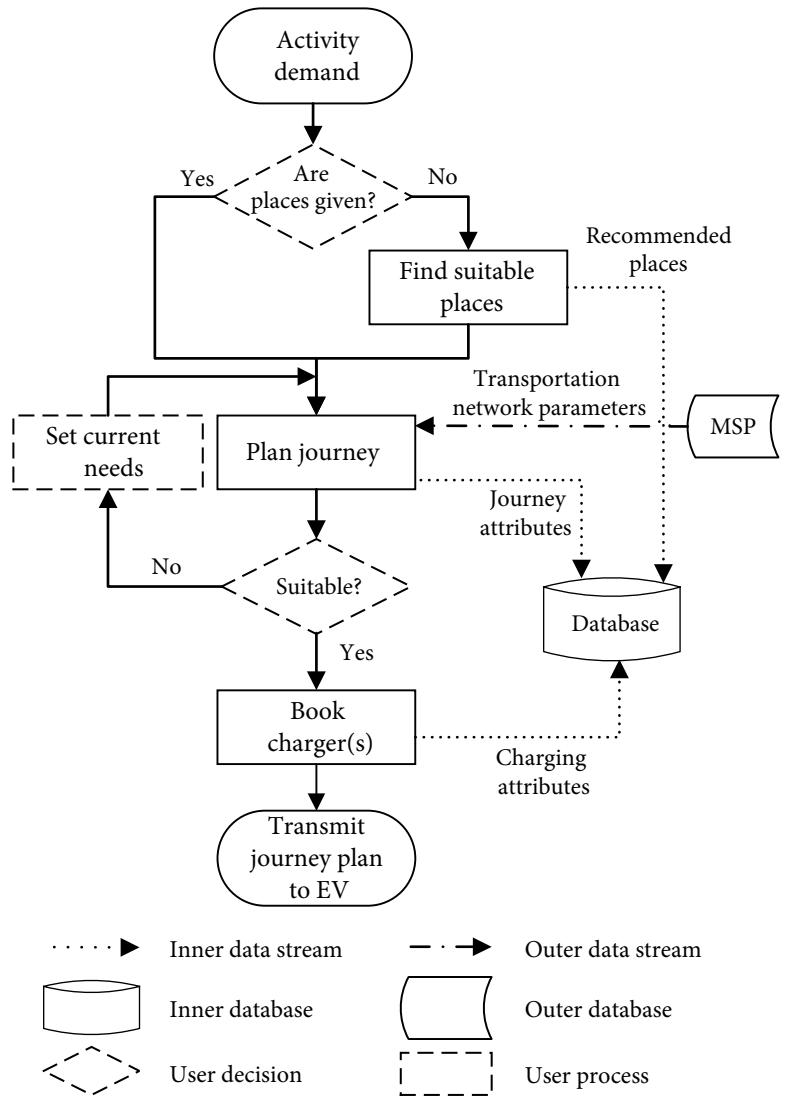

Figure 3. Flow-chart of journey planning 
the "current needs", that are valid for a specific journey, can be also set, such as:

- the minimum PEV range when arriving at a charging station (e.g. to reduce range anxiety),

- the preference of charger types (e.g. only superchargers),

- the maximum duration of one charging session,

- route optimisation target (e.g. fastest/balanced/lowest energy consumption),

- charging optimisation target (e.g. shortest/battery friendly (low charging power)/balanced charging time).

Since queue time at charging points extends the travel time the dynamic information on charging point availability and booking options are especially important.

The function is also accessible on route. Furthermore, information on driving characteristic and energy consumption as well as advice to improve energy efficiency can be also provided by $F_{2}$.

\subsection{Charging assistance $\left(F_{3}\right)$}

The charging session can be initialized and finished by $\mathrm{F}_{3}$ while dynamic information on the session is also provided. Figure 4 displays the charging assistance process indicating also the data streams. After the vehicle has been

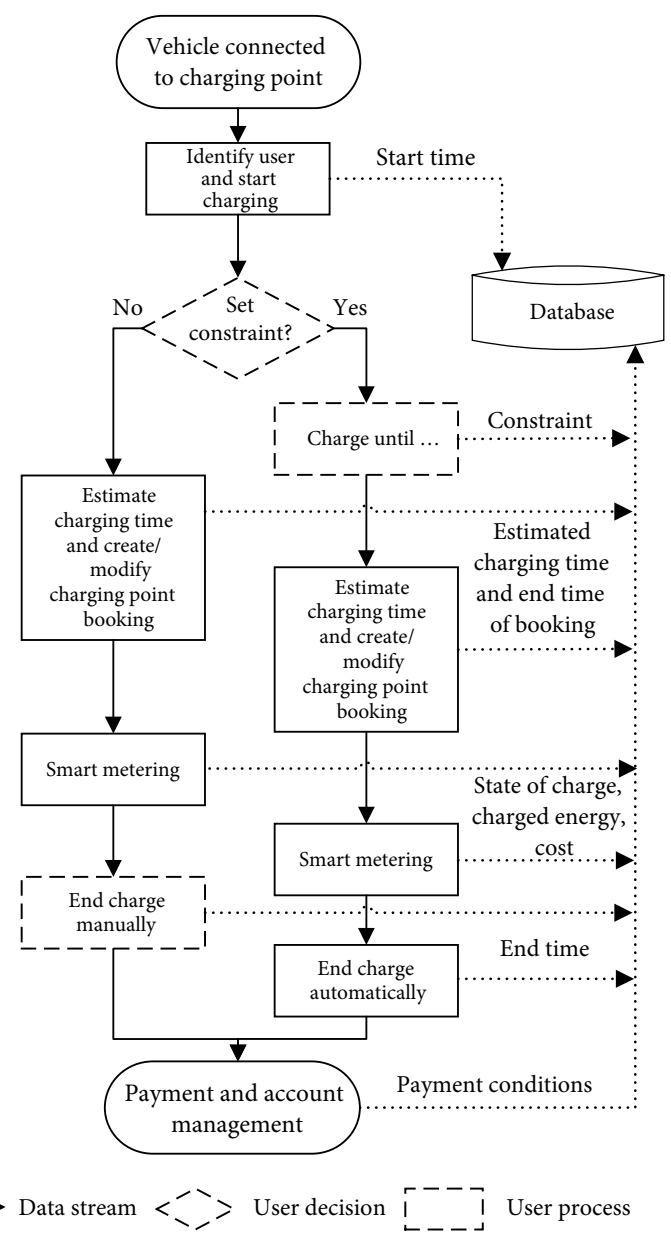

Figure 4. Flow-chart of charging assistance connected to a charging point, the user is identified with the smartphone application, access card or by vehicle and then the charging starts automatically.

The charging session can be finished in two ways:

- manually;

- by setting a condition.

Conditions can be related to the maximum transmitted energy $[\mathrm{kWh}]$, maximum cost $[€]$, finish time of charge $[-:-]$, state of charge [\%] or range $[\mathrm{km}]$.

If charging condition is not set, the estimated time equals the time required to fully charge the battery. During charging, real-time information on charging is provided as a consequence of periodical update of cumulative data e.g. state of charge, charged energy, cost.

The payment can be performed in two ways:

- manually: the user initiates the payment;

- automatically: the application initiates the payment (the user is notified about the transaction).

\subsection{Charging scheduling $\left(F_{4}\right)$}

Charging cost can be reduced by charging scheduling $F_{4}$ if the variable rate of electricity is introduced. The application of variable rate and charging scheduling together is an efficient tool to influence charging behaviour and equalize electricity demand. A schedule consists of charging and supply time periods $T_{G 2 V}$ and $T_{V 2 G}$.

In the case of "manual" scheduling, the user is informed about the electricity rates and accordingly decides about the timing of charging. In the case of "automatic" scheduling, the timing is determined by $F_{4}$. The aim of automatic scheduling is to minimise the user's cost of charging according to the range requirement and electricity rates. We define the following automatic charging scheduling modes:

- charge only schedule: the supply operation is not allowed;

- charge and supply schedule: the charge only schedule is extended by supply operation.

The detailed description of the scheduling processes is given in Section 4. In case of the "automatic" charging schedule the user may set the following variables:

- travel demand: minimum range of the PEV $R_{\min }$ and the estimated travel distance of an upcoming trip $R_{e, k}$; several $R_{e, k}(k=1, \ldots, n)$ can be set;

- charging sessions (where and when the vehicle is expected to be connected to a charging point $t_{\text {start }}$ and $t_{\text {end }} ;$

- charging mode (charge only or charge and supply schedule).

The location of charging session is important because of the charging point attributes, that are stored in the database of SYS (e.g. power). Electricity rate is given by the Smart Grid. The user can not set a trip distance if the charging time is not enough to reach that range. If the current range of a PEV is lower than $R_{\min }$, then the vehicle is continuously charged regardless of electricity rates until its range is greater than or equals to $R_{\min }$. Hence, the user 
can set several charging sessions and travel distances in advance to reduce the chance that the current range of a PEV falls under $R_{\min }$.

During the modelling of the "automatic" charging scheduling modes, we made the following presumptions:

- the vehicle can pause charging and change between charge and supply operation during a charging session;

- the cost of charging is based on the amount of electric energy [kWh] transmitted and electricity rates;

- the user can sell the energy stored in the PEV's battery to the Smart Grid;

- the PEV cannot be in charging and supply mode at once.

Figure 5 summarises the main steps of charging scheduling.

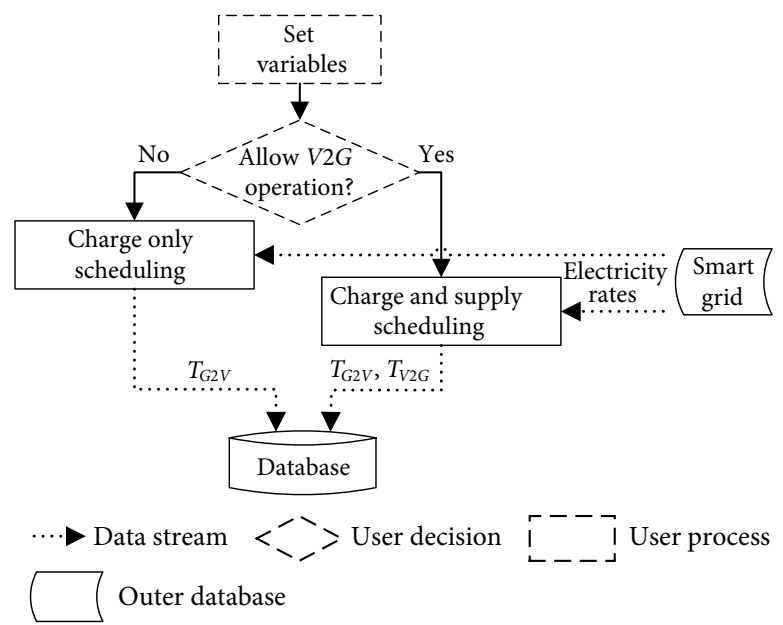

Figure 5. Flow-chart of charging scheduling

\section{Automatic charging scheduling methods}

The "automatic" charging scheduling methods have been elaborated in detail.

\subsection{Charge only scheduling}

In the case of "charge only scheduling" method, the following additional presumptions were considered:

- the electricity rate may change at any time;

- the electricity rate is given in advance (e.g. published by Smart Grid); Otherwise, the minimum cost of charging is not achievable.

The steps of the method are the following:

1. Those periods when the PEV is not expected to be connected to a charging point are ignored;

2. The charging sessions are divided into equalamount-energy sections. Each section has the same amount of energy; however, the duration of sections may differ. Since $1 \mathrm{~min}$ charging at $3 \mathrm{~kW}$ (general charging power at home in EU) is about $0.5 \mathrm{kWh}$, we recommend $0.5 \mathrm{kWh}$ amount of energy for sections;
3. The purchase price $C_{p}$ of each section is determined according to electricity rate and amount of energy;

4. The energy demand of the trips is estimated on the base of travel distance $R_{e, k}$;

5. $R_{\min }$ requirement is checked at each $t_{\text {start }}$ and $R_{e, k}$ requirements at each $t_{\text {end }}$ to determine the duration of charging periods. The requirements are checked in a chronological order. The sub-steps are the following: 5.1. The first moment when a range requirement is not fulfilled is selected. The first $R_{\min }$ requirement is ignored due to the lack of predicted previous charging session;

5.2. The not selected and not ignored energy sections before the selected moment where $C_{p}$ is the lowest are listed;

5.3. It selects an energy section from the result list where the charging time is the minimum;

5.4. The energy section is added to the charging schedule.

Sub-steps of Step 5 are repeated until the sum of the chargeable amount of energy in selected energy sections is enough to fulfil the range requirements.

Figure 6 displays the steps of charge only scheduling method and the estimated current range of the PEV $R_{c}$ curves. The $4 R_{c}$ curves mean that the charging periods are added to the schedule in 3 steps to fulfil the 3 different range requirements $-R_{\min }, R_{e, 1}$ and $R_{e, 2}$.

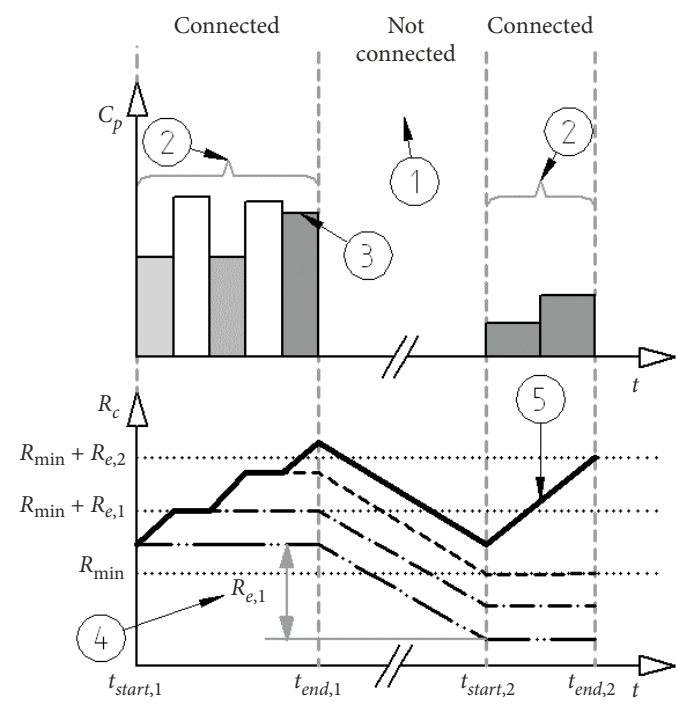

Not selected section:

Section added to charging schedule to fulfil the range requirement of:
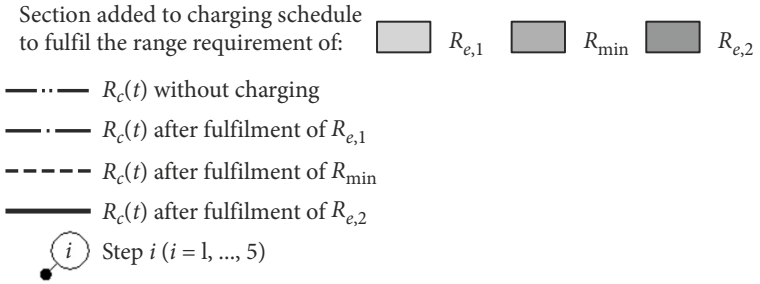

Figure 6. Charge only scheduling and current range of PEV as a function of time $R_{c}(t)$ 


\subsection{Charge and supply scheduling}

Supply scheduling is performed after the charge scheduling, which is performed in a similar way as in case of the charge only scheduling. During the development of the supply scheduling method, we considered the following additional presumption. The sale price of electricity (in supply mode) is never higher than the purchase price (in charging mode).

The steps of the supply scheduling method are the following:

1. The charging sessions are divided into equalamount-energy sections;

2. The sale price $C_{s}$ of each energy section (Figure 7) is determined;

3. The free supply sections are sorted by descending price, and free charging sections by ascending price (Figure 8);

4. The optimum amount of energy $E_{\text {opt }}$, where the profit of supply mode $P_{V 2 G}$ is maximum, is determined. The optimum amount of energy is where the amount of chargeable energy is maximum and the sale price is lower than or equal to purchase price $C_{s}(E) \leq C_{p}(E) . P_{V 2 G}$ is the difference between the benefit from sold energy $B_{V 2 G}$ and cost of extra charging demand $C_{V 2 G}$. The maximum profit is presented on Figure 9 if the amount of energy of sections converges to 0 ;

5. Each energy section before $E_{\text {opt }}$ (both supply and charge) is added to the charging schedule;

6. It is checked that whether $R_{\min }$ or $R_{e, k}$ requirements after supply mode periods are fulfilled or not. If not, there are two ways to raise the range:

6.1. Reduce supply mode. In this case, the loss is the lost partial profit;

6.2. Increase charging mode. In this case, the loss is the increment of charging cost.

The option with the lower loss is selected.

According to Figure 9, $P_{V 2 G}, B_{V 2 G}$ and $C_{V 2 G}$ are calculated based on Equations (1)-(3):

$$
\begin{aligned}
P_{V 2 G}(E) & =B_{V 2 G}(E)-C_{V 2 G}(E) ; \\
B_{V 2 G}(E) & =\int_{0}^{E} C_{s}(E) d E \\
C_{V 2 G}(E) & =\int_{0}^{E} C_{p}(E) d E .
\end{aligned}
$$

\section{Simulation of automatic charging scheduling modes}

We made a simulation to reveal and demonstrate the effects of electricity rate variables and forethoughtful charging behaviour on the cost saving. The aim was to compare charging modes in term of charging cost. The basic modes that lack the support of the SYS was compared with the automatic charging scheduling modes.

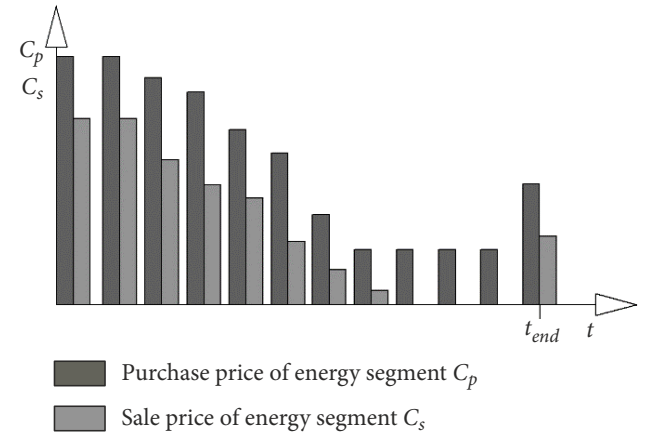

Figure 7. Sale and purchase price of energy sections in chronological order

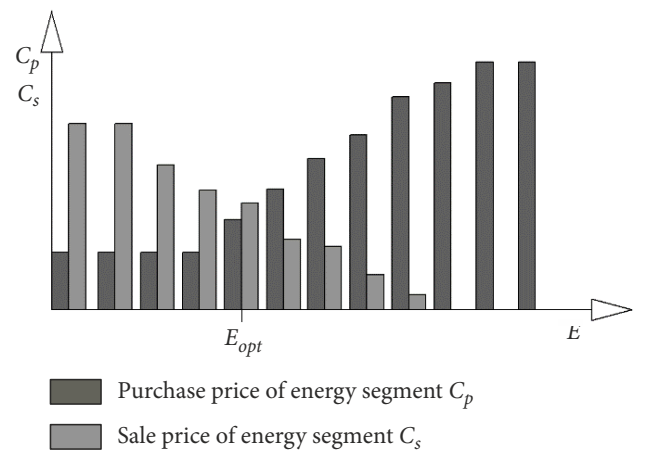

Figure 8. Sale and purchase price of energy sections in order by price

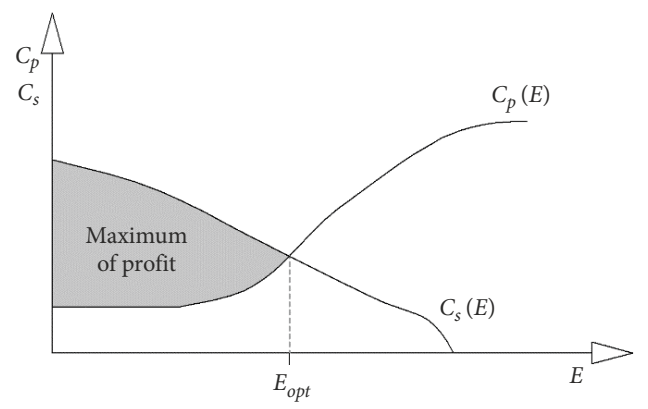

Figure 9. Maximum of profit of supply mode if the amount of energy of sections converges to 0

\subsection{Simulation attributes}

We assume $50 \mathrm{kWh}$ battery capacity of a BEV and it is always connected to the electric grid when not being in movement. The simplified energy consumption of PEV is $7.5 \mathrm{kWh} / \mathrm{h}$ in movement. The charging power is always $3.6 \mathrm{~kW}$.

We assume a variable electricity rate that follows the fluctuation of daily energy demand. Both $C_{p}$ and $C_{s}$ may change in every $20 \mathrm{~min}$ to follow the rapid changes of the energy demand. We considered the average daily energy demand fluctuation in the UK (ESO 2017). The energy price has been defined according to the demand: when the demand is the lowest, the cost is minimal $\left(C_{p}^{\min }\right)$; when the demand is the highest, the cost is maximal $\left(C_{p}^{\max }\right)$, which is approximately $50 \%$ more than the minimal value. Between these limits, the $C_{p}$ values are calculated with linear interpolation. The average daily fluctuation of $C_{p}$ that was used during the simulation is given in Figure 10. 


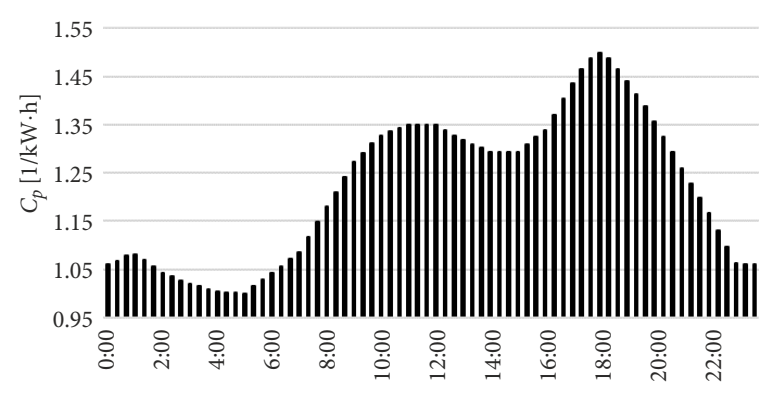

Figure 10. Average daily fluctuation of $C_{p}$ in simulation $\left(C_{p}^{\max } / C_{p}^{\min }=1.5\right)$

We set different cases to simulate both the daily routine and the preparation for a long-distance trip. The cases are the following:

- daily routine: we analysed a 24 -hour period with short trips;

- long-distance trip: we considered high range requirement at a certain $t_{\text {end }}$.

The schedules are described in Tables 4 and 5. The basic charging modes are as follows:

- always charge: vehicle is usually charged until 100\%; in the case of long-distance trip, the vehicle is charged until the range requirement is fulfilled;

- home charge: vehicle is always charged until 100\% but only at home (night time charging); usually in the early evening.

Furthermore, we made a sensitivity analysis to reveal the effects of difference between $C_{p}$ and $C_{s}$, the difference

Table 4. Schedule of daily short trips

\begin{tabular}{|c|c|c|}
\hline Time & Status of vehicle & Minimal SOC requirement [\%] \\
\hline $20: 40 \ldots 7: 20$ & at home & 25 \\
\hline $7: 20 \ldots 8: 20$ & in movement & - \\
\hline $8: 20 \ldots 17: 00$ & not at home & 20 \\
\hline $17: 00 \ldots 17: 40$ & in movement & - \\
\hline $17: 40 \ldots 19: 40$ & not at home & 30 \\
\hline $19: 40 \ldots 20: 40$ & in movement & - \\
\hline
\end{tabular}

Table 5. Schedule of the long-distance trip

\begin{tabular}{|c|c|c|c|}
\hline \multirow{4}{*}{ Day } & Time & $\begin{array}{c}\text { Status } \\
\text { of vehicle }\end{array}$ & $\begin{array}{c}\text { Minimal SOC } \\
\text { requirement [\%] }\end{array}$ \\
\hline \multirow{4}{*}{$\begin{array}{l}\text { First } \\
n \text { day }\end{array}$} & $0: 00 \ldots 7: 20$ & at home & 25 \\
\cline { 2 - 4 } & $7: 20 \ldots 8: 20$ & in movement & - \\
\cline { 2 - 4 } & $8: 20 \ldots 17: 00$ & not at home & 20 \\
\cline { 2 - 4 } & $17: 00 \ldots 17: 40$ & in movement & - \\
\cline { 2 - 4 } & $17: 40 \ldots 19: 40$ & not at home & 30 \\
\cline { 2 - 4 } & $19: 40 \ldots 20: 40$ & in movement & - \\
\cline { 2 - 4 }$(n+1)$ & $20: 40 \ldots 0: 00$ & at home & - \\
\cline { 2 - 4 } day & $0: 00 \ldots 7: 20$ & at home & 25 \\
\cline { 2 - 4 } & $7: 20 \ldots 8: 20$ & in movement & - \\
\hline \multirow{2}{*}{} & $8: 20 \ldots 17: 00$ & not at home & 90 \\
\hline
\end{tabular}

between the minimum and maximum $C_{p}$ throughout a day and the time when the range requirement is set. Our starting hypotheses were the following:

- the benefit of the use of automatic charging scheduling increase if either the fluctuation of electricity rate or the difference between $C_{p}$ and $C_{s}$ increase;

- the difference between the automatic charging scheduling modes vanishes if the difference between $C_{p}$ and $C_{s}$ is rather low;

- the earlier the user set the range requirement, the greater the benefit of the use of automatic charging scheduling is.

\subsection{Simulation results and discussion}

At first, we revealed the effect of the rate of $C_{p}^{\max }$ and $C_{p}^{\min }$ on the charging cost. We compared the 2 basic and the 2 automatic charging scheduling modes. We made the simulation for a daily routine. The other variables were constant. The charging costs of different charging modes are displayed on Figure 11.

Both automatic charging scheduling mode is better than the basic modes in the term of charging cost. Charging costs in case of home charging and charge only scheduling is close to each other, however, the latter one is less sensitive to the change of tariff fluctuation because the charging process performed in the valley period when the fluctuation of the tariff is much lower than during early evening. The charging cost in case of charge and supply mode decreases because $B_{V 2 G}$ increases at a higher rate than the total cost of charging periods. Furthermore, it is not recommended for the user to always charge its vehicle.

In the second step, we examined the sensitivity of charging cost as a function of $C_{s} / C_{p}$ during a daily routine for charge and supply scheduling mode. The result is displayed on Figure 12.

The difference between charge only and charge and supply mode vanishes if the rate of $C_{s} / C_{p}$ is low. In our case, $C_{s} / C_{p}=0.7$ is the border (Figures 9 and 10). If the rate of $C_{s} / C_{p}$ decreases, the length of time periods when supply mode is beneficial decreases. Thus, a high $C_{s} / C_{p}$ rate is needed to efficiently encourage $\mathrm{BEV}$ users to use charging and supply mode. Hence, a high-power charger is recommended for charge and supply mode, because it raises the amount of tradable energy in supply mode. Furthermore, a high-power home charger efficiently raises the energy demand on the grid at night. However, usually, an inexpensive slow charger is recommended for home charging, which is more battery friendly.

Finally, we analysed the effect of forethoughtful behaviour before a long-distance trip. We present the charging cost as a function of how much time before the range requirement was set in Figure 13.

Automatic charging schedules perform better than the basic modes and the difference is slightly increasing with time. Charging cost unit for automatic charging schedules is decreasing because the flexibility of charging and supply operation schedule is increasing with time. Thus, the vehicle can be charged when the electricity rate is low. 


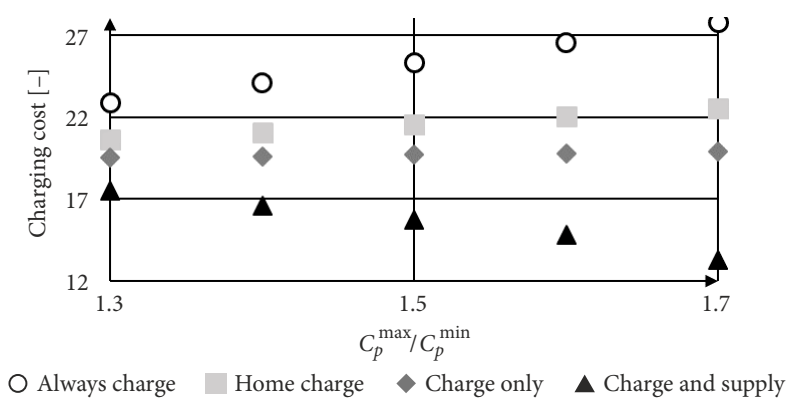

Figure 11. Charging cost of daily routine as a function of electricity rate fluctuation when $\left(C_{s} / C_{p}=0.95\right)$

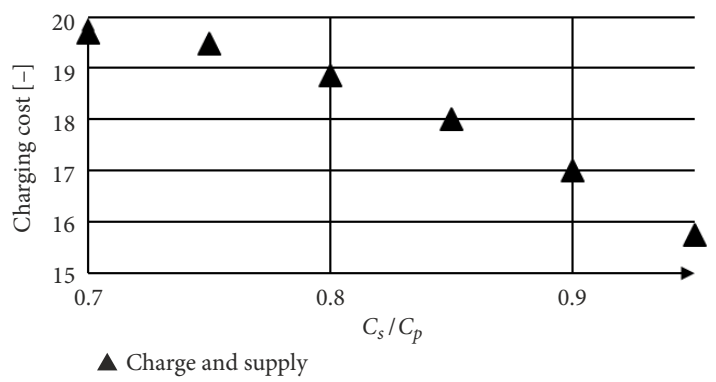

Figure 12. Charging cost of daily routine in case of charge and supply mode as a function of the rate of $C_{s}$ and $C_{p}$ $\left(C_{p}^{\max } / C_{p}^{\min }=1.5\right)$

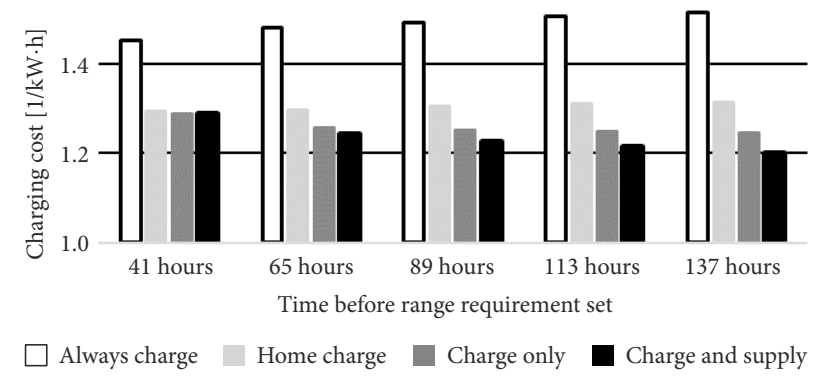

Figure 13. Charging cost according to setting time

$$
\left(C_{p}^{\max } / C_{p}^{\min }=1.5\right) \text { and }\left(C_{s} / C_{p}=0.95\right)
$$

The charging cost of home charging is slightly increasing. The reason for this phenomenon is that in general the vehicle is fully charged during the first evening, and during the other evenings the vehicle is charged to serve the energy demand of the daily routine. The average energy rate during the first evening is lower because it contains the valley period. In contrast to the other evenings, when the vehicle is mostly charged in the early evening when the rate is higher. The same phenomenon is valid for always charge mode. The limits at infinity of cost units for each charging mode are equals to the charging cost units for the daily routine because the cost of extra charging is negligible compared to the cost of the daily energy needs.

According to the results, the automatic charging schedule modes decrease the charging cost in each case. However, the difference depends on the variable rates and the set time of range requirements. The key findings of the simulation are as follows:
- if $C_{p}^{\max } / C_{p}^{\min }$ and $C_{s} / C_{p}$ are high (1.7 and 0.95), the use of charge only and charge and supply mode decrease the charging cost of daily routine by 12 or $41 \%$ compared to home charging;

- an early set of high range requirement (137-hour before) decreases the charging cost (5.3 and $8.7 \%)$ in case of charge only and charge and supply mode.

\section{Conclusions}

The main contribution of the paper in comparison with previous works is the model of an integrated IS that includes the novel automatic charging scheduling modes. The condition of the integration was to reveal the relations between system components, functions and data groups. The advanced service facilitates the spread of PEVs as the functions of the SYS have been assigned to the main drawbacks of PEVs. The elaborated charging scheduling method is an efficient tool to minimize the charging cost and plan the charge according to the travel needs. The advanced IS that is connected to the Smart Grid decreases the fluctuation in the electricity demand and may earn profit for the user in supply mode. Accordingly, the introduction of the method is beneficial for both the users and the organizations participating in electric energy supply.

According to our simulation results, the efficiency of the method highly depends on the variable electricity rates and the time when the range requirement is set. We revealed the effect of the rate of minimum and maximum electricity costs, as well as the difference between the sale and purchase prices. Depending on the rates, the automatic charging schedule may reduce the charging cost even by $5.3 . .41 \%$. In general, if the sale price is rather low (in our simulation $70 \%$ of purchase price), the benefit of supply mode is zero. Hence, a high sale price and fluctuation is recommended to encourage PEV users to use the supply mode. It also found that cost saving requires a more forethoughtful driving behaviour from PEV users.

Counter to previous findings that recommend a slow charging at night, from an electric grid point of view a higher power charger is recommended, that is more suited to electricity demand equalization. Beyond the electricity rates, the battery capacity of the PEV and the charging power, especially where the vehicle is charged at night, influence the benefit of supply mode. Thus, the further research direction is to reveal the impact of vehicle and charger variables on the charging and supply mode from the electric grid point of view. Finally, the use of machine learning techniques to enhance the user experience of ISs is also a promising field of research in the future.

\section{Acknowledgements}

The research reported in this paper was supported by the Higher Education Excellence Program of the Ministry of Human Capacities in the frame of Artificial Intelligence research area of Budapest University of Technology and Economics (BME FIKP-MI/FM). 


\section{References}

Caparello, N. D.; Kurani, K. S. 2012. Households' stories of their encounters with a plug-in hybrid electric vehicle, Environment and Behavior 44(4): 493-508. https://doi.org/10.1177/0013916511402057

Cowan, K. R. 2013. A New roadmapping technique for creatively managing the emerging smart grid, Creativity and Innovation Management 22(1): 67-83. https://doi.org/10.1111/caim.12017

Csiszár, C.; Földes, D. 2015. Analysis and modelling methods of urban integrated information system of transportation, in 2015 Smart Cities Symposium Prague (SCSP), 24-25 June 2015, Prague, Czech Republic, 1-10. https://doi.org/10.1109/SCSP.2015.7181574

Dagsvik, J. K.; Wennemo, T.; Wetterwald, D. G.; Aaberge, R. 2002. Potential demand for alternative fuel vehicles, Transportation Research Part B: Methodological 36(4): 361-384. https://doi.org/10.1016/S0965-8564(01)00013-1

ESO. 2017. Electricity System Operator (ESO) in Great Britain. Available from Internet: https://www.nationalgrid.com

Esztergár-Kiss, D; Csiszár, C. 2016. Multicriteria analysis of Hungarian journey planners, Periodica Polytechnica Transportation Engineering 44(2): 97-104. https://doi.org/10.3311/PPtr.8570

Guille, C; Gross, G. 2009. A conceptual framework for the vehicle-to-grid (V2G) implementation, Energy Policy 37(11): 4379-4390. https://doi.org/10.1016/j.enpol.2009.05.053

Hernández, L.; Baladrón, C.; Aguiar, J. M.; Calavia, L.; Carro, B.; Sánchez-Esguevillas, A.; Cook, D. J.; Chinarro, D.; Gómez, J. 2012. A study of the relationship between weather variables and electric power demand inside a smart grid/smart world framework, Sensors 12(9): 11571-11591. https://doi.org/10.3390/s120911571

Herrala, M. 2007. The Value of Transport Information. VTT Technical Research Centre, Finland. 98 p. Available from Internet: https://www.vtt.fi/inf/pdf/tiedotteet/2007/T2394.pdf

Hidrue, M. K.; Parsons, G. R.; Kempton, W.; Gardner, M. P. 2011. Willingness to pay for electric vehicles and their attributes, Resource and Energy Economics 33(3): 686-705. https://doi.org/10.1016/j.reseneeco.2011.02.002

Hu, J.; Morais, H.; Sousa, T.; Lind, M. 2016. Electric vehicle fleet management in smart grids: a review of services, optimization and control aspects, Renewable and Sustainable Energy Reviews 56: 1207-1226. https://doi.org/10.1016/j.rser.2015.12.014

Khoo, H. L.; Asitha K. S. 2016. User requirements and route choice response to smart phone traffic applications (apps), Travel Behaviour and Society 3: 59-70. https://doi.org/10.1016/j.tbs.2015.08.004

Kiviluoma, J.; Meibom, P. 2011. Methodology for modelling plug-in electric vehicles in the power system and cost estimates for a system with either smart or dumb electric vehicles, Energy 36(3): 1758-1767. https://doi.org/10.1016/j.energy.2010.12.053

Krupa, J. S.; Rizzo, D. M.; Eppstein, M. J.; Lanute, D. B.; Gaalema, D. E.; Lakkaraju, K.; Warrender, C. E. 2014. Analysis of a consumer survey on plug-in hybrid electric vehicles, Transportation Research Part A: Policy and Practice 64: 14-31. https://doi.org/10.1016/j.tra.2014.02.019

Lawrence, D. B. 1999. The Economic Value of Information. Springer. 393 p. https://doi.org/10.1007/978-1-4612-1460-1

Mal, S.; Chattopadhyay, A.; Yang, A.; Gadh, R. 2013. Electric vehicle smart charging and vehicle-to-grid operation, International Journal of Parallel, Emergent and Distributed Systems 28(3): 249-265. https://doi.org/10.1080/17445760.2012.663757
Philipsen, R.; Schmidt, T.; Ziefle, M. 2015. A charging place to be - users' evaluation criteria for the positioning of fastcharging infrastructure for electro mobility, Procedia Manufacturing 3: 2792-2799. https://doi.org/10.1016/j.promfg.2015.07.742

Rietveld, P. 2011. The economics of information in transport, in A. de Palma, R. Lindsey, E. Quinet, R. Vickerman (Eds.). A Handbook of Transport Economics, 586-603. https://doi.org/10.4337/9780857930873.00033

Shao, S.; Pipattanasomporn, M.; Rahman, S. 2009. Challenges of PHEV penetration to the residential distribution network, in 2009 IEEE Power \& Energy Society General Meeting, 26-30 July 2009, Calgary, Canada, 1-8. https://doi.org/10.1109/PES.2009.5275806

Sutherland, E. 2013. Forrester: The iPhone is Still Most-Used Smartphone. Available from internet: https://www.idownloadblog.com/2013/08/01/iphone-most-used-smartphone

ThinkMobile. 2011. The Mobile Movement: Understanding Smartphone Users. 39 p. Available from internet: https://ssl.gstatic. com/think/docs/the-mobile-movement_research-studies.pdf

Wang, T.-G.; Xie, C.; Xie, J.; Waller, T. 2016. Path-constrained traffic assignment: A trip chain analysis under range anxiety, Transportation Research Part C: Emerging Technologies 68: 447-461. https://doi.org/10.1016/j.trc.2016.05.003

Wydro, K. B. 2010. A measurement of the information value in transport processes, Communications in Computer and Information Science 104: 210-217. https://doi.org/10.1007/978-3-642-16472-9_23

Yang, Y.; Yao, E.; Yang, Z.; Zhang, R. 2016. Modeling the charging and route choice behavior of BEV drivers, Transportation Research Part C: Emerging Technologies 65: 190-204. https://doi.org/10.1016/j.trc.2015.09.008

Zheng, C.; Xu, G.; Xu, K.; Pan, Z.; Liang, Q. 2015. An energy management approach of hybrid vehicles using traffic preview information for energy saving, Energy Conversion and Management 105: 462-470.

https://doi.org/10.1016/j.enconman.2015.07.061 